\title{
Molecular Docking study of Receptor Binding Domain of SARS-CoV-2 Spike Glycoprotein with Saikosaponin, a Triterpenoid Natural Product
}

\author{
T. Goswami, ${ }^{1} *$ Bhaskar Bagchi, ${ }^{2}$ \\ ${ }^{1}$ Department of Chemistry, Raiganj University, Raiganj- 733134, India \\ ${ }^{2}$ Madhabnagar Badalmoni High School, Malda- 732103, India \\ *Email: tamaltgoswami@gmail.com \\ Ph: +91-9475816410
}

\begin{abstract}
The appearance of SARS-CoV-2 has resulted $\sim 19000$ deaths and $\sim 423000$ infections worldwide as of March 24, 2020. Coronavirus spike (S) glycoproteins hooks on target cells and binds to the angiotensin-converting enzyme 2 (ACE2) receptor. Recent researches speculated that residues 331 to 524 of the $\mathrm{S}$ glycoprotein of the receptor binding domain (RDB) of the spike is the most crucial target and this side was very important for computational docking. In the present study we have considered a series of saikosaponins and molecular docking was performed. Most of the docked molecules bind favorably to the RDB region of the spike glycoprotein and among them Saikosaponin B4 is the best inhibitor.
\end{abstract}

\section{Introduction}

The recent occurrence and spread of Coronavirus Disease - 2019 (COVID-19) has emerged as a serious global threat in many fronts. The disease has caused $\sim 19000$ deaths and $\sim 423000$ infections worldwide as of March 24, 2020. The exponential growth of infections has led the World Health Organization to characterize the disease as a pandemic on March 11, 2020. The deadly atypical pneumonia is caused by 2019 novel coronavirus (2019-nCoV), which is discovered during December 2019 in Wuhan, Hubei Province of China and was isolated and sequenced very recently. ${ }^{1,2} 2019-\mathrm{nCoV}$, termed as severe acute respiratory syndrome (SARS) coronavirus-2 (SARS-CoV-2), has more transmission-rate than the other two known highly pathogenic human coronaviruses, namely, Middle East respiratory syndrome coronavirus (MERS-CoV), severe acute respiratory syndrome (SARS) coronavirus (SARS-CoV). ${ }^{3}$

It has been found that coronaviruses are comprised of four structural proteins, namely, spike (S), envelope (E), membrane (M), and nucleocapsid (N) proteins. ${ }^{4}$ Among them, S protein is located at the surface of the pathogen and is most crucial to attach itself to host receptor with a subsequent fusion and entry to host cell. ${ }^{5}$ The transmembrane spike (S) glycoprotein forms homotrimers that stick out from the viral surface. ${ }^{6}$ Each $\mathrm{S}$ glycoprotein is composed of two functional subunits, namely, S1 and S2 subunits. Among them the S1 subunit is responsible for binding to the host cell receptor and the S2 subunit causes fusion of the viral and cellular membranes. ${ }^{7,8}$ 
The entry of SARS-CoV-2 into host cell, recognized as the first step of viral infection, is mediated by binding of the S1 subunit of the spike protein to the host cell receptor through the receptor binding domain(s) of the $\mathrm{S} 1$ subunit. The $\mathrm{S} 1$ subunit is also divided into domain $\mathrm{A}$ and $\mathrm{B}$ for convenience. It has already been evidenced that SARS-CoV-2 S glycoprotein binds favorably to the human Angiotensin-converting enzyme 2 (hACE2) receptor through the S1B domain of the S1 subunit of the spike protein. ${ }^{9-12}$ Tai et. al. ${ }^{5}$ very recently have identified residues 331 to 524 of the $\mathrm{S}$ glycoprotein as the receptor binding domain (RDB) of the spike. With this advancement, it is apparent that this $\mathrm{RDB}$ is the most crucial target for finding appropriate inhibitors, antibodies or vaccines to stop entry of the virus in the host cell. The homotrimer of SARS-CoV-2 is $160 \AA$ long and very closely resembles other two much studied coronaviruses. ${ }^{5}$ The homotrimer of SARS-CoV-2 S glycoprotein and a monomer protein are shown in Figure 1a and $1 \mathrm{~b}$ respectively. The RDB of the $\mathrm{S}$ glycoprotein is highlighted in yellow in Figure $1 b$.

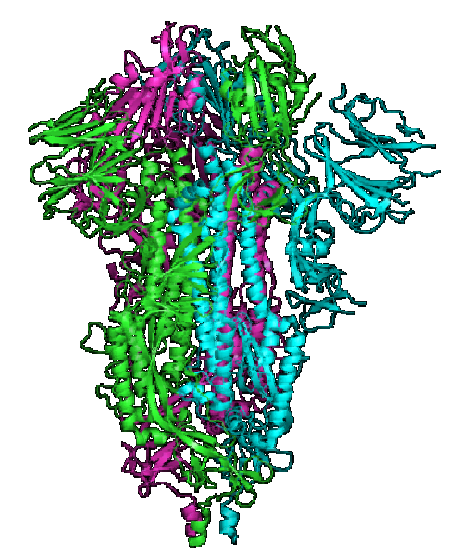

Side View

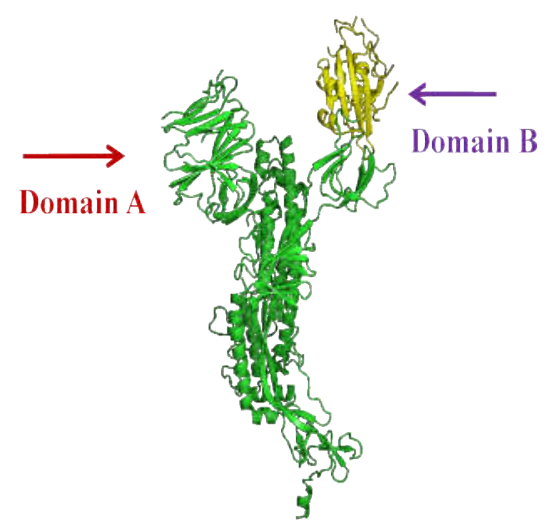

Front View

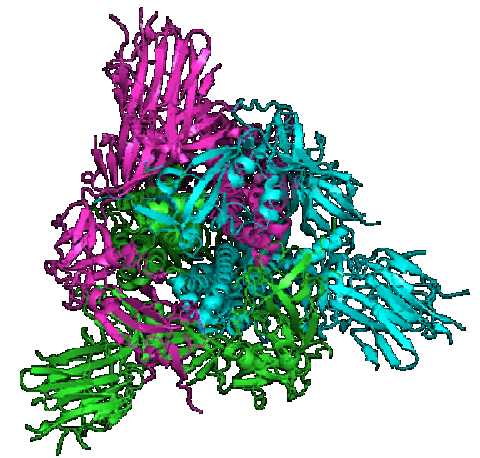

Top View

(a)

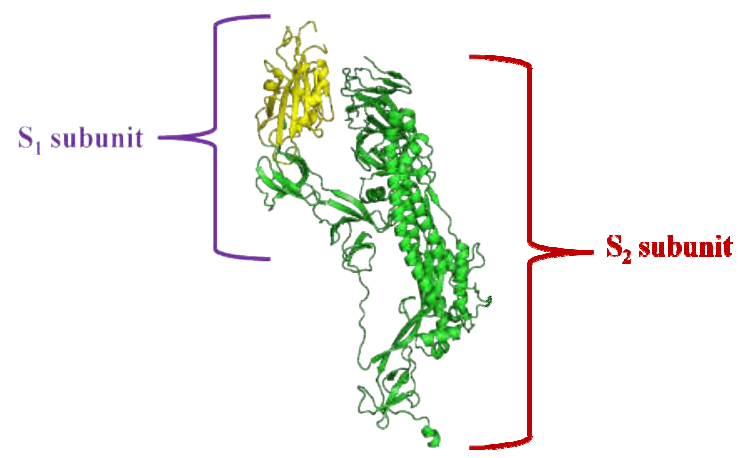

Side View

(b)

Figure 1. (a) Homotrimer of transmembrane spike glycoprotein of SARS-CoV-2. Three different colors represent three monomers $\mathrm{S}$ glycoprotein. (b) The monomer of $\mathrm{S}$ glycoprotein with different domains and subunits designated. The receptor-binding-domain has been drawn in yellow. 
Natural products are rich source of antiviral molecules. It has been analyzed that $\sim 70 \%$ of the anti-infectives (including anti-virals) are from natural sources than of synthetic origin. ${ }^{13}$ Also the ethnomedicinal products such as culinary herbs, spices etc. reflect the effectiveness of natural products as anti-virals. Phytochemicals from different chemical classes, e.g., alkaloids, terpenoids, coumarins, essential oils, flavonoids, phytosterols, polysaccharides, polyphenols, tannins, saponins, proteins, and peptides have been proved to be effective in therapeutic applications in various viral infections. ${ }^{14-16}$ Bupleurum roots (Radix Bupleuri) are traditionally used in Eastern Asia as herbal treatments for influenza, fever, hepatitis, malaria, etc. for its antioxidant, anti-inflammatory, antibacterial, antiviral and anticancer effects. ${ }^{17}$ Chemical characterization of the herb revealed the presence of bioactive triterpene saponin glycosides, known as saikosapnins. ${ }^{18}$ Saikosaponins have been reported to have antiviral effects. ${ }^{19}$

In the present study we considered a series of saikosaponins, namely, Saikosaponin A (i), B1 (ii), B2 (iii), B3 (iv), B4 (v), C (vi), D (vii), E (viii) and I (ix), to assess their interaction with the B domain of the S1 subunit of SARS-CoV-2 spike glycoprotein through molecular docking. The 3D structures of the molecules (i) through (ix) are presented in Figure 2. Molecular docking is a popular and extensively tested method in structure base drug design. Due to its ability to predict ligand binding conformation to macromolecules, viz., proteins, molecular docking is very crucial in computer aided drug design. Keeping in mind the urgency of testing and developing drug for COVID-19, we herein report binding of saikosaponin molecules to the RDB of the S glycoprotein, which may play effective role in interfering in the re-folding process of the spike and thereby inhibit viral entry to host. The results can be further substantiated through higher level calculation which is kept as a future prospect of this work. Studies with other members of saikosaponin family are also due for future work.

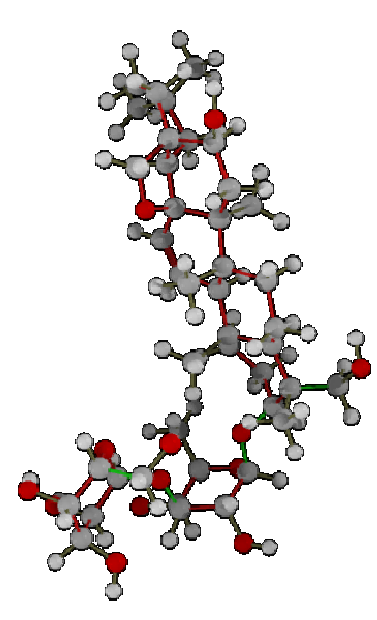

(i)

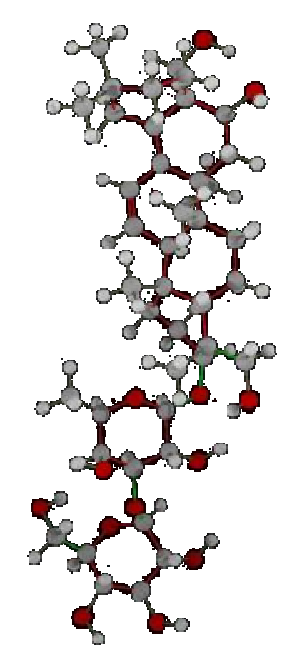

(ii)

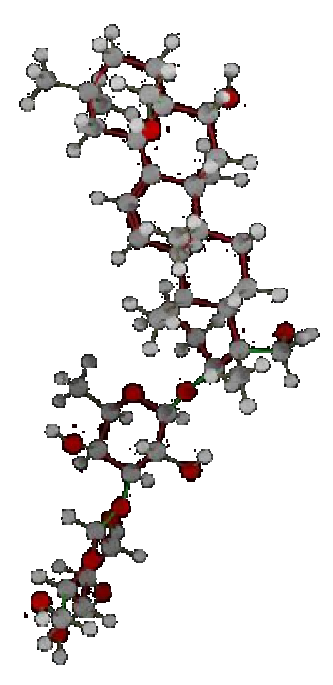

(iii) 


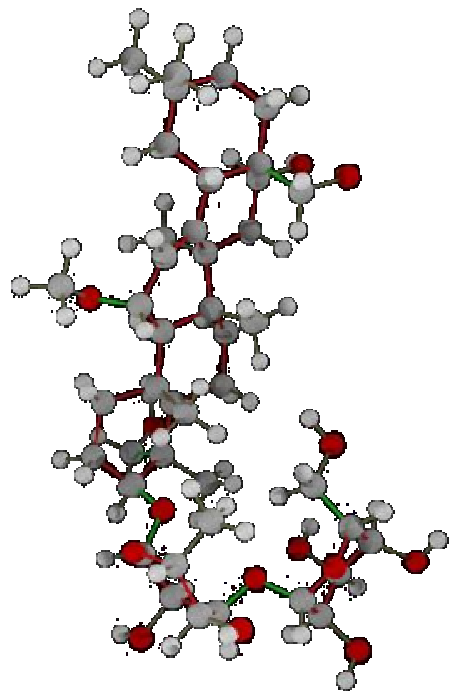

(iv)

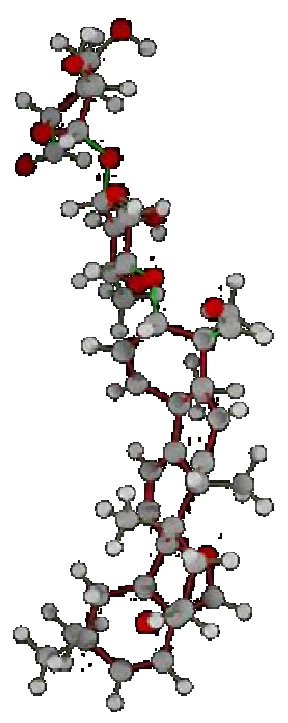

(vii)

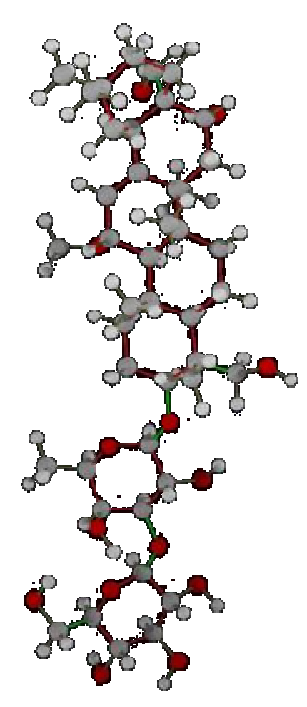

(v)

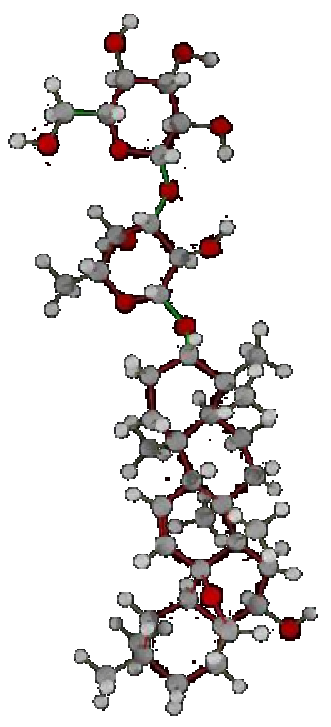

(vii)

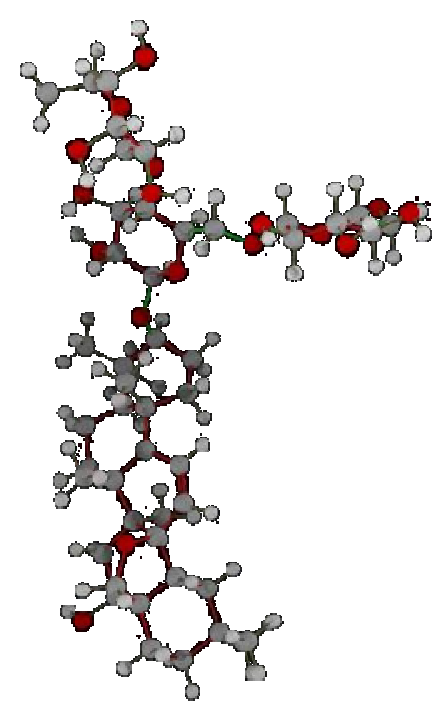

(vi)

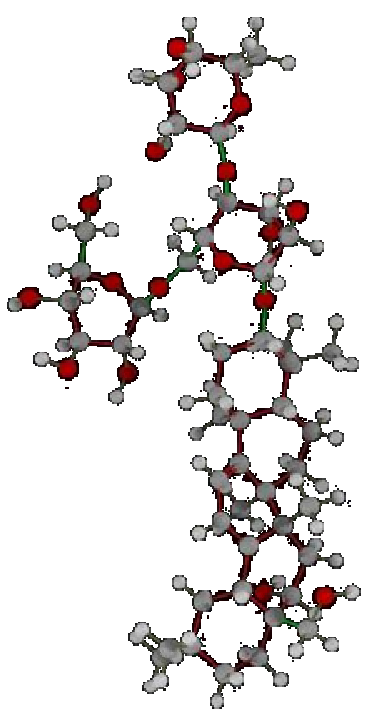

(ix)

Figure 2. Three dimensional structures of the nine Saikosaponins, namely, Saikosaponin A (i), B1 (ii), B2 (iii), B3 (iv), B4 (v), C (vi), D (vii), E (viii) and I (ix) that are considered for the present study. 


\section{Methods}

Molecular dockings of a series of saikosaponins are performed with the docking program Autodock Vina v1.1. ${ }^{20}$ The choice of Autodock Vina as docking software is advocated to be highly efficient as well as fast to find bioactive conformations with a very good level of accuracy. $^{21}$ The Autodock graphical interface AutoDockTools ${ }^{22,23}$ was used to keep polar hydrogens and add partial charges to the proteins. The search space was included in a box of 120 $\times 120 \times 120 \AA^{3}$, covering the B domain of the S1 subunit of the SARS-CoV-2 S glycoprotein. For each calculation, fifteen poses ranked according to the scoring-function of Autodock Vina were obtained. The results were analyzed through PyMOL ${ }^{24}$ and Molegro Molecular Viewer $2.5^{25}$ visualization programs. It is often suggested to perform rescoring based on post-docking optimizations for refinement of docked conformation and improved insight of ligand protein interaction. Hence we performed rescoring of the docked conformations using MolDock program. $^{25}$

\section{Results and Discussion}

The interactions of saikosaponin genre of terpenoids with the B domain of S1 subunit of spike glycoprotein of SARS-CoV-2 are studied in reference to possible inhibition of the binding of the RDB of the glycoprotein with host cell. The AutoDock Vina Docking scores and the MolDock scores are used as the key parameters to assess the ligand-protein interactions. The docked poses are presented in Figure 3 along with the residues of the protein with which the saikosaponin molecules interact.

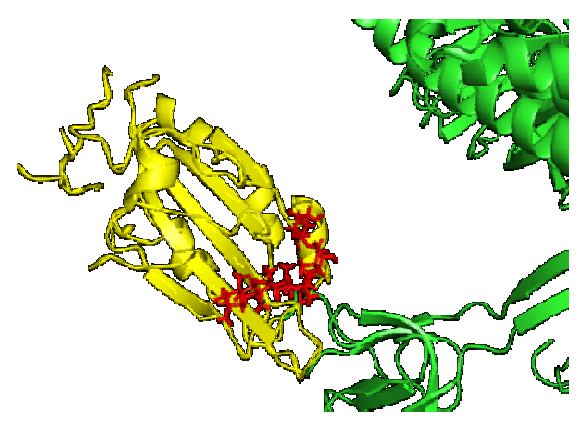

(i)

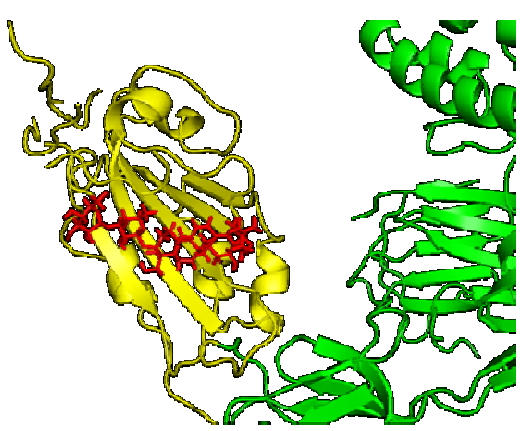

(ii)

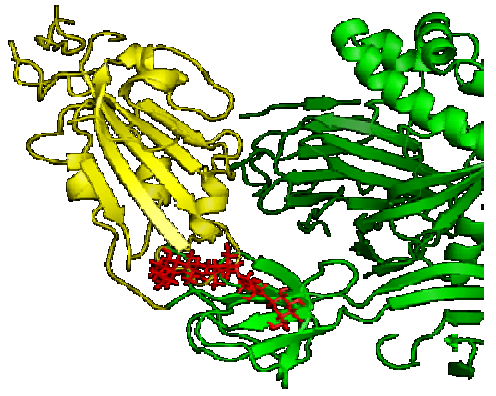

(iii) 


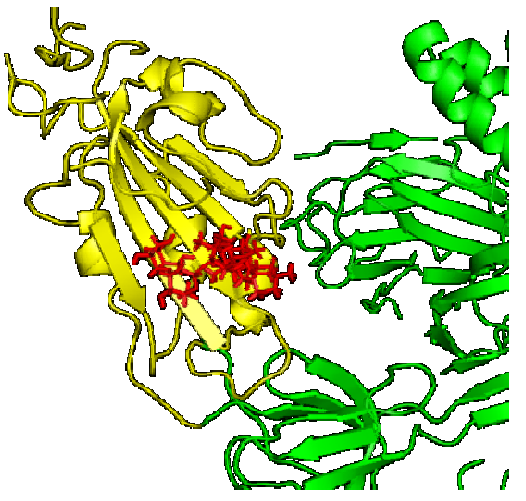

(iv)

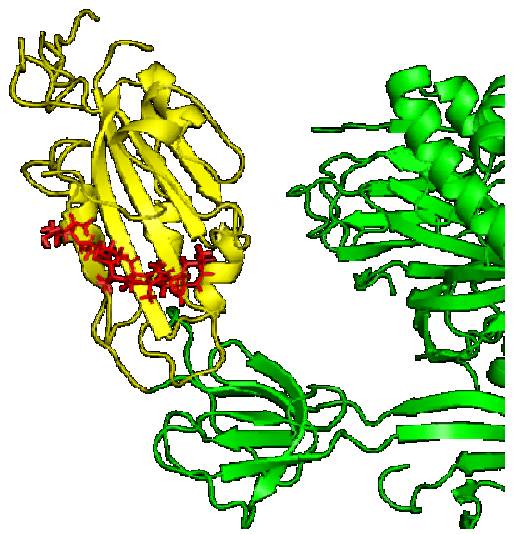

(vii)

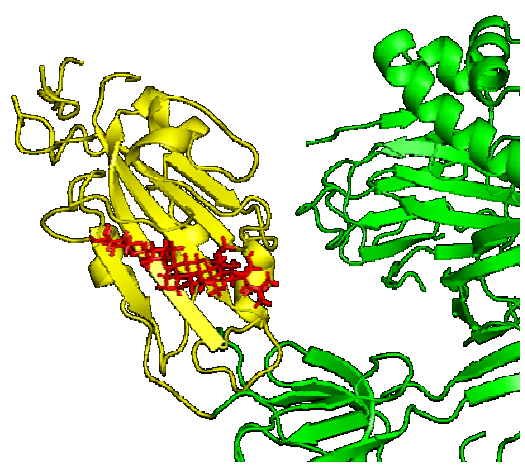

(v)

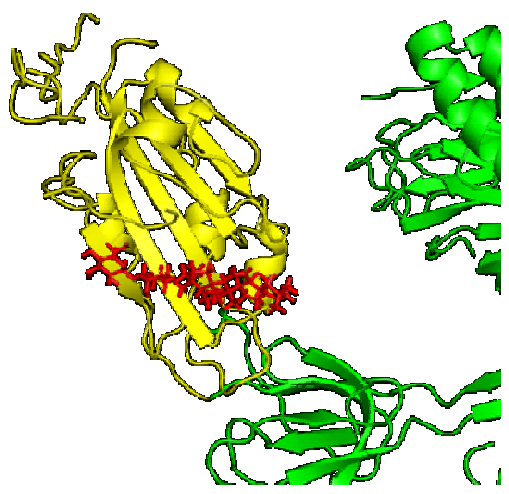

(viii)

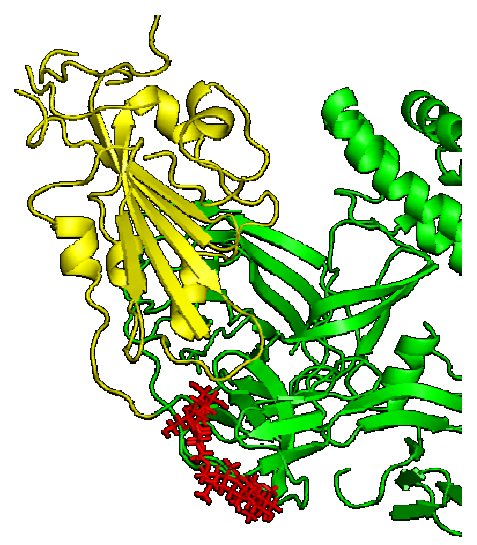

(vi)

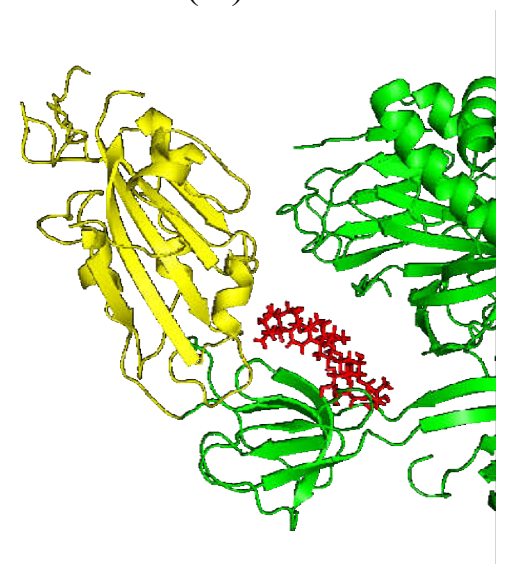

(ix)

Figure 3. The lowest energy docked poses of the Saikosaponins A (i) through I (ix) performed in AutoDock Vina. The yellow domain represents RDB of SARS-CoV-2 S glycoprotein.

From a close observation of Figure 3 it can be understood that saikosaponins B2(iii), $\mathrm{C}(\mathrm{vi})$ and I(ix) does not bind to the RDB directly but the other six ligands namely, A(i), B1(ii), B3(iv), B4(v), D(vii) an E(viii) binds to the desired RDB of the spike protein. Hence, a critical analysis is necessary to assess the performance of the saikosaponins in binding to the SARSCoV-2 S glycoprotein. Table 1 reports the detailed interaction energy of the protein with the ligand saikosaponin molecules. The individual interactions of the ligand molecules with different residues of the RDB are also reported along with the total binding energy. From comparison of the energy values it can be predicted that the best ligand to interfere with the $\mathrm{S}$ protein binding to host cell is saikosaponin B4. 
Table 1. The Vina scores and MolDock scores of the saikosaponin molecules with the RDB of the spike protein.

\begin{tabular}{|c|c|c|c|c|c|c|}
\hline \multirow[t]{2}{*}{ Moecule } & \multirow[t]{2}{*}{ Image } & \multicolumn{3}{|c|}{$\begin{array}{c}\text { Interaction Energy with } \\
\text { different residues of } S \\
\text { glycoprotein } \\
\end{array}$} & \multirow{2}{*}{$\begin{array}{l}\text { Vina Score } \\
\text { (kcal/mol) }\end{array}$} & \multirow{2}{*}{$\begin{array}{l}\text { MolDock Score } \\
\text { (kcal/mol) }\end{array}$} \\
\hline & & Res & ID & $\begin{array}{c}\text { Energy } \\
(\mathrm{kcal} / \mathrm{mol})\end{array}$ & & \\
\hline (i) & 1 & $\begin{array}{l}\text { Gly } \\
\text { Tyr } \\
\text { Tyr } \\
\text { Asp } \\
\text { Arg } \\
\text { Pro } \\
\text { Phe } \\
\text { Phe } \\
\text { Ser } \\
\text { Phe } \\
\text { Leu } \\
\text { Leu } \\
\text { Thr } \\
\text { Glu } \\
\text { Asp }\end{array}$ & $\begin{array}{l}381 \\
380 \\
396 \\
427 \\
355 \\
426 \\
429 \\
515 \\
514 \\
464 \\
517 \\
518 \\
430 \\
516 \\
428\end{array}$ & $\begin{array}{r}-0.43 \\
-0.70 \\
-0.72 \\
-1.70 \\
-1.76 \\
-2.27 \\
-5.45 \\
-6.72 \\
-7.01 \\
-7.91 \\
-7.92 \\
-13.52 \\
-14.18 \\
-15.31 \\
-21.59\end{array}$ & -10.6 & -53.78 \\
\hline
\end{tabular}




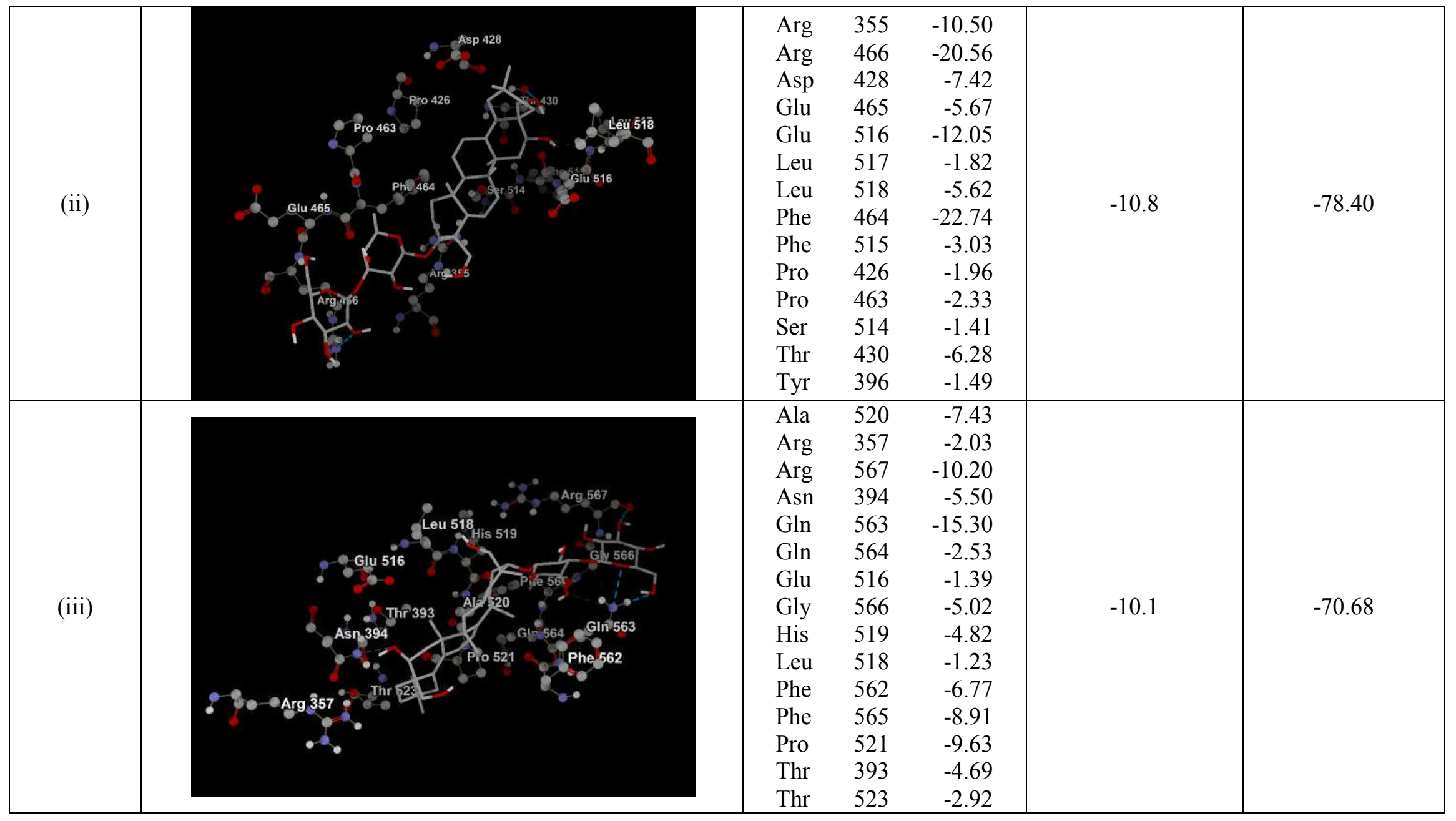




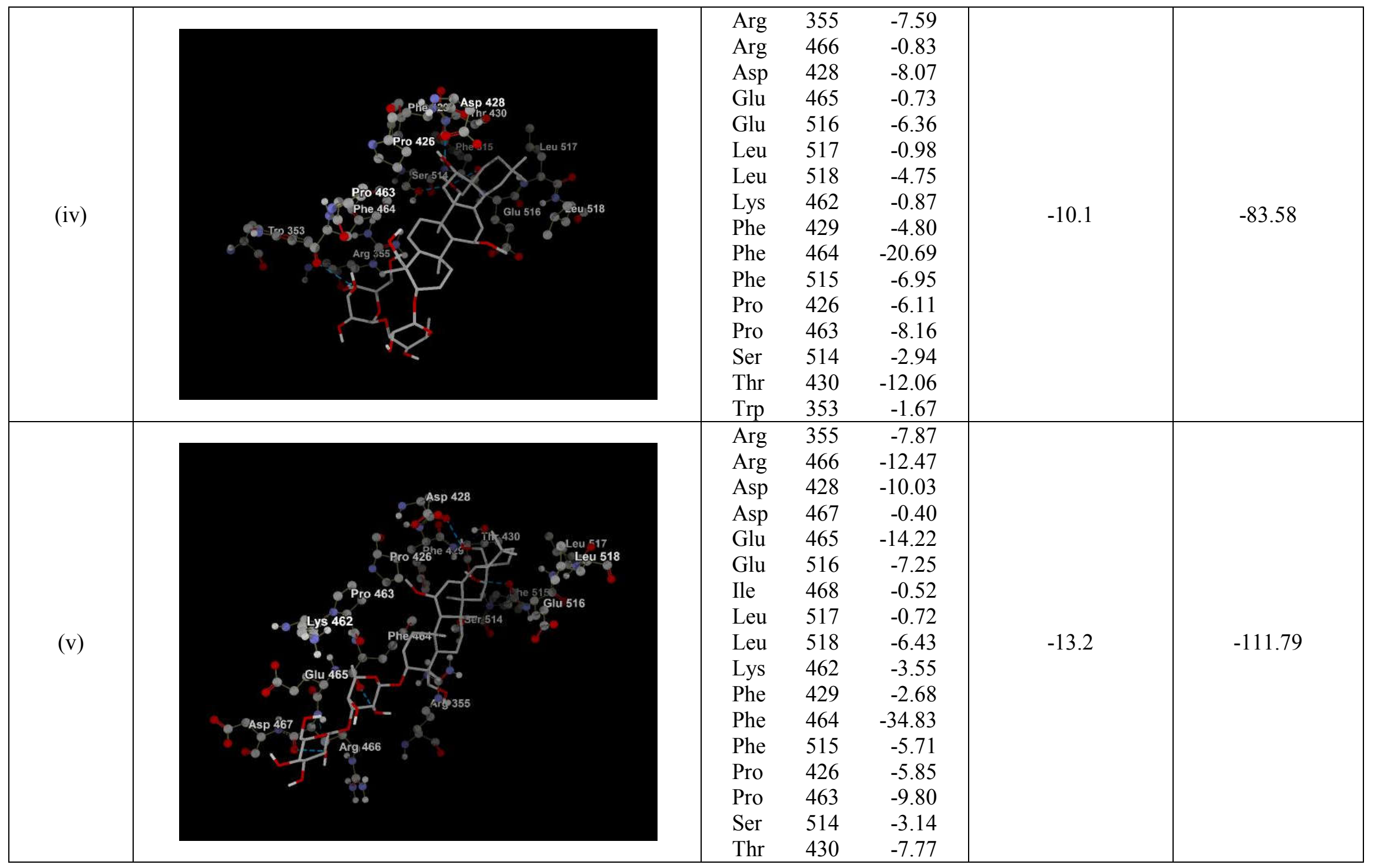




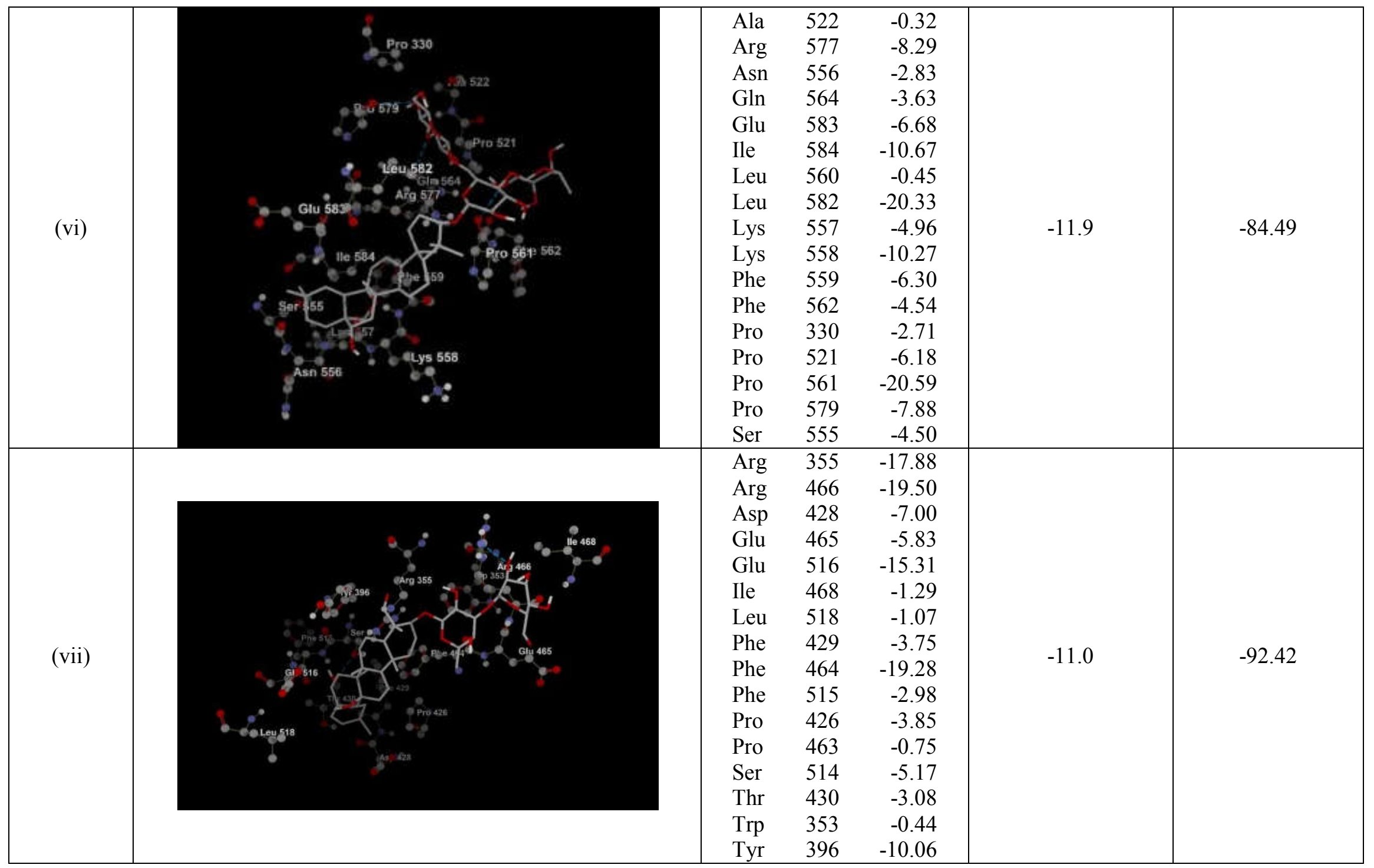




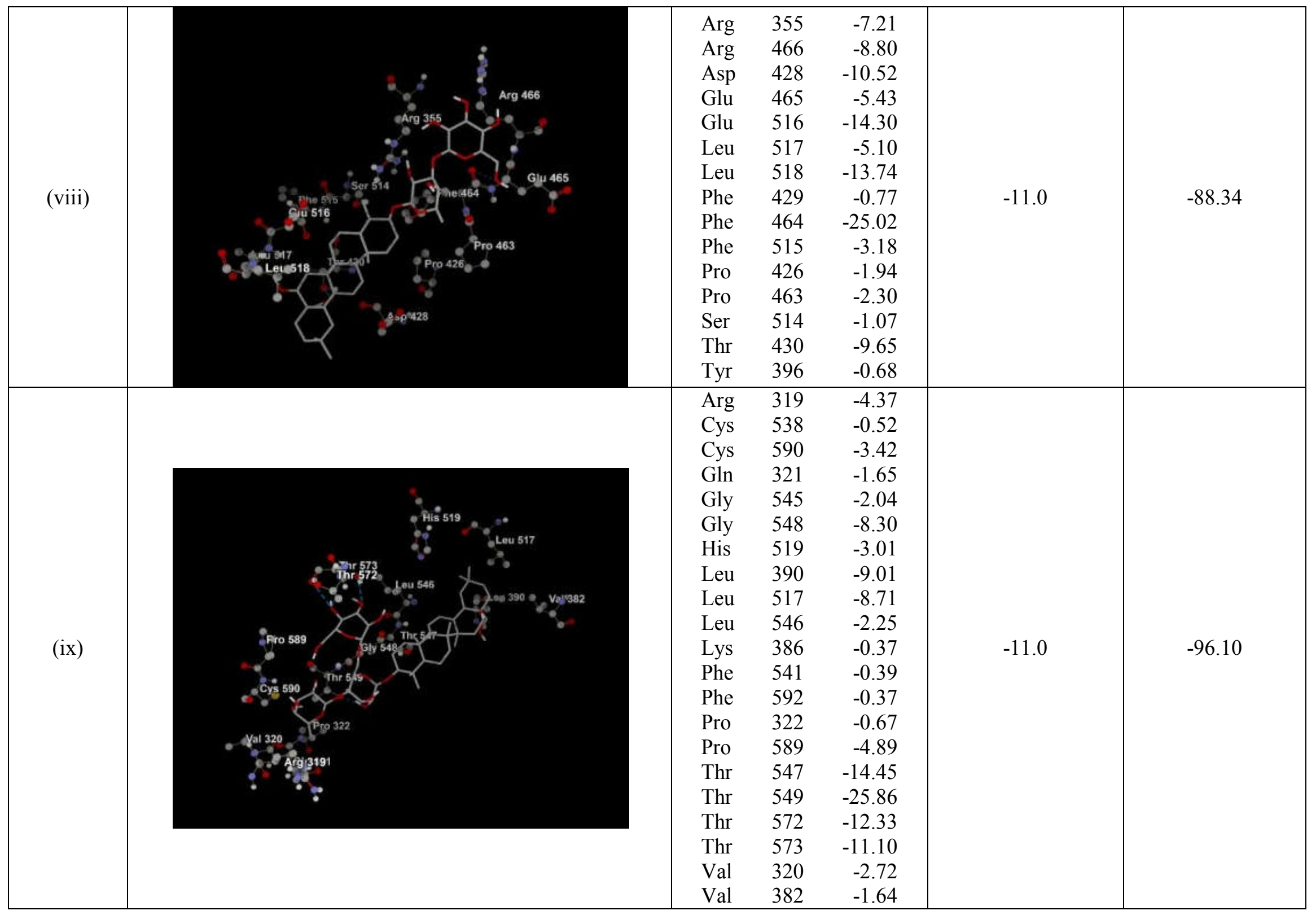




\section{Conclusion}

The present study focuses on the efficacy of saikosaponin class of triterpenoids in inhibiting the binding of the RDB of SARS-CoV-2 spike glycoprotein with host receptor through molecular docking. Although majority of the docked molecules bind favorably to the RDB region of the spike glycoprotein, saikosaponin B4 is the best inhibitor among the molecues under study. The results clearly indicate that the selected terpenoids shows strong binding affinity towards the RDB of the spike glycoprotein and thus can interfere with attachment of SARS$\mathrm{CoV}-2$ with host cells inhibiting the very first stage of viral infection.

\section{References}

1. Zhou, P.; Yang, X.L.; Wang, X.G.; Hu, B.; Zhang, L.; Zhang, W.; Si, H.R.; Zhu, Y.; Li, B.; Huang, C.L.; et al., Nature, 2020, 579, 270.

2. Zhu, N.; Zhang, D.; Wang, W.; Li, X.; Yang, B.; Song, J.; Zhao, X.; Huang, B.; Shi, W.; Lu, R.; et al., N. Engl. J. Med., 2020, 382, 727.

3. World Health Organization. Coronavirus disease 2019 (COVID-19)-Situation report-45, 2020, https://www.who.int/docs/default-source/coronaviruse/situationreports/20200305-sitrep-45covid-19.pdf?sfvrsn=ed2ba78b_2.

4. Zhou, Y.; Jiang, S.; Du, L., Expert Rev. Vaccines, 2018, 17, 677.

5. Tai, W.; He, L.; Zhang, X.; Pu, J.; Voronin, D.; Jiang, S.; Zhou, Y.; Du, L., Cell Mol. Immunol., 2020, doi: https://doi.org/10.1038/s41423-020-0400-4.

6. Tortorici, M.A.; Veesler, D., Adv. Virus. Res., 2019, 105, 93.

7. Li, F.; Li, W.; Farzan, M.; Harrison, S. C., Science, 2005, 309, 1864.

8. Lu, L.; Liu, Q.; Zhu, Y.; Chan, K. H.; Qin, L.; Li, Y.; et al., Nat. Commun., 2014, 5, 3067.

9. Lu, R.; Zhao, X.; Li, J.; Niu, P.; Yang, B.; Wu, H.; et al., Lancet, 2020, 395, 565.

10. Wan, Y.; Shang, J.; Graham, R.; Baric, R. S.; Li, Fang, J. Virol., 2020, 94, e00127.

11. Hoffmann, M.; Kleine-Weber, H.; Krüger, N.; Müller, M.; Drosten, C.; Pöhlmann, S., The novel coronavirus $2019(2019-\mathrm{nCoV})$ uses the SARS-coronavirus receptor ACE2 and the cellular protease TMPRSS2 for entry into target cells. bioRxiv 2020, 2020.01.31.929042.

12. Wrapp, D.; Wang, N.; Corbett, K. S.; Goldsmith, J. A.; Hsieh, C.L.; Abiona, O.; et al., Science, 2020, 367, 1260.

13. Newman, D. J.; Cragg, G. M., J. Nat. Prod., 2007, 70, 461. 
14. Chattopadhyay, D., Mod. Phytomed., 2006, 15, 313.

15. Cos, P.; Vanden Berghe, D.; De Bruyne, T.; Vlietinck, A. J., Curr. Org. Chem., 2003, 7, 1163.

16. Vlietinck, A. J.; De Bruyne, T.; Vanden Berghe, D.A., Curr. Org. Chem., 1997, 1, 307.

17. Lin, L.T., Chung, C.Y., Hsu, W.C., Chang, S.P., Hung, T.C., Shields, J., et al., J. Hepatol., 2015, $62,541$.

18. Pan, S. L., Bupleurum Species: Scientific Evaluation and Clinical Applications, 1st ed. Boca Raton: CRC Press/Taylor \& Francis Group; 2006.

19. Lin, L.T.; Hsu, W.C.; Lin, C.C., J. Tradit. Complement. Med., 2014, 4, 24.

20. Trott, O.; Olson, A. J., J. Comput. Chem., 2010, 31, 455.

21. Alvarez, A.C.; Costa A.M.; Vilarrasa, J., Molecules., 2017, 22, 136.

22. Sanner, M. F.; Duncan, B. S.; Carrillo, C. J.; Olson, A. J., Pac. Symp. Biocomput., 1999, 4, 401.

23. Morris, G. M.; Huey, R.; Lindstrom, W.; Sanner, M. F.; Belew, R. K.; Goodsell, D. S.; Olson, A. J., J. Comput. Chem., 2009, 30, 2785.

24. The PyMOL Molecular Graphics System, Version 1.2r3pre, Schrödinger, LLC.

25. Thomsen, R.; Christensen, M. H., J. Med. Chem., 2006, 49, 3315. 